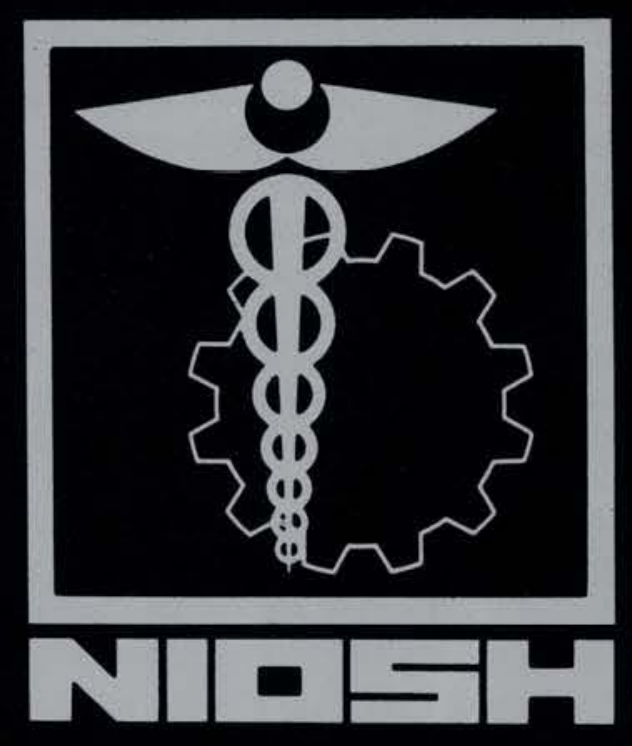

\title{
Proposed National Strategies for the Prevention of Leading Work - Related Diseases and Injuries - Occupational Lung Diseases •
}

U.S. DEPARTMENT OF HEALTH AND HUMAN SERVICES

Public Health Service Centers for Disease Control National Institute for Occupational Safety and Health 


\section{Proposed National Strategy for the Prevention of Occupational Lung Diseases}

U.S. DEPARTMENT OF HEALTH AND HUMAN SERVICES Public Health Service Centers for Disease Control National Institute for Occupational Safety and Health NIOSH LIESARY SYSTEM 
DHHS (NIOSH) Publication No. 89-128 


\section{Introduction}

This document, $A$ Proposed National Strategy for the Prevention of Occupational Lung Diseases, summarizes what actions need to be taken to prevent occupational lung diseases. It was developed in 1985 at a conference sponsored by the National Institute for Occupational Safety and Health (NIOSH) and The Association of Schools of Public Health (ASPH), which brought together over 50 expert panelists and 450 other occupational safety and health professionals.

In addition to the strategy for occupational lung diseases, NIOSH and ASPH have published strategies for the other nine leading occupational diseases and injuries: musculoskeletal injuries, occupational cancers, severe occupational traumatic injuries, occupational cardiovascular diseases, disorders of reproduction, neurotoxic disorders, noise-induced hearing loss, dermatological conditions and psychological disorders.

The proposed strategies were originally published in a two volume set, Proposed National Strategies for the Prevention of Leading Work-Related Diseases and Injuries, Part 1 and Part 2. These proposed strategies are not to be considered as final statements of policy of NIOSH, The Association of Schools of Public Health, or of any agency or individual who was involved. Hopefully, they will be used in the quest to prevent disease and injury in the workplace.

To learn of the availability of the complete texts of Part 1 and Part 2, or to obtain additional copies of this or other Strategies, contact NIOSH Publications, 4676 Columbia Parkway, Cincinnati, Ohio 45226. Telephone (513) 533-8287. 


\section{A Proposed National Strategy for the Prevention of Occupational Lung Diseases}

\section{Occupational Lung Diseases: Problems and Goals}

The lung is both a target organ and a portal of entry for toxic substances. The likelihood of toxic exposure can be high; for example, an estimated 1.2 million workers each year are potentially exposed to silica dust alone. Early recognition of occupational lung diseases is difficult because the latent period for such diseases may be as long as 15 years for silicosis and 30 years or more for asbestos-related cancers. Other factors, such as cigarette smoking, may contribute significantly to disease processes and hence obscure the association between disease and toxic exposure at work.

The United States Public Health Service has established the following national objectives for the prevention of occupational lung diseases: "By 1990, among workers newly exposed after 1985, there should be virtually no new cases of four preventable occupational lung diseases-asbestosis, byssinosis, silicosis, and coal workers' pneumoconiosis." These four chronic lung diseases will be used as examples in the. prevention strategy. To the extent that they are typical of most occupational lung diseases, potential prevention methods available for their control are not unique.

\section{Definition and Classification of Occupational Lung Diseases}

Occupational lung disease is caused by the inhalation of toxic substances present in the work environment. Lung damage is seldom indicative of the specific injuring agent. Therefore, the recognition of occupational respiratory illness may be obscured by the nonspecificity of symptoms, lung function, radiographic findings, and even occasionally pathologic manifestations. In addition, occupational exposures are often multiple or mixed, symptoms may be minimal until disease is advanced, and latency periods may be long. Work-related lung disease may be further complicated by cigarette smoking and its independent or synergistic effects on the lung. Thus, the association between lung disease and occupational exposure is not always apparent or simple. 
Classification of occupational lung disease represents an attempt to provide meaningful associations from available information. From the perspective of disease prevention, perhaps the most useful means of classification is by type of exposure (Table 1.). This scheme permits the rapid identification of toxicants and illustrates the spectrum of their diseases. By categorizing substances in this manner, the applicability of available control technology can be readily addressed. Consistent with this approach, the four diseases identified in the 1990 Objectives (asbestosis, byssinosis, silicosis, and coal workers' pneumoconiosis) would be classified by exposure (asbestos, cotton dusts, silica, and coal dust). This document will use the exposure classification scheme.

Table 1. Examples of Occupational Lung Diseases

\begin{tabular}{|c|c|c|}
\hline Agent & Examples of Agents & Disease/Response \\
\hline \multirow{3}{*}{$\begin{array}{l}\text { Inorganic } \\
\text { Dusts }\end{array}$} & Crystalline silica & Silicosis* \\
\hline & Asbestos & $\begin{array}{l}\text { Asbestosis*, lung cancer, } \\
\text { mesothelioma }\end{array}$ \\
\hline & Coal dust & Coal workers' pneumoconiosis* \\
\hline \multirow{3}{*}{$\begin{array}{l}\text { Organic and } \\
\text { Metallic Dusts }\end{array}$} & Cotton, flax, hemp & Byssinosis* \\
\hline & $\begin{array}{l}\text { Proteins, metallic } \\
\text { salts, antibiotics, } \\
\text { chemicals (TDI, TMA) }\end{array}$ & Occupational asthma \\
\hline & $\begin{array}{l}\text { Moldy hay, grain, sugar cane, } \\
\text { contaminated humidifiers }\end{array}$ & Hypersensitivity pneumonitis \\
\hline $\begin{array}{l}\text { Gases and } \\
\text { Fumes }\end{array}$ & $\begin{array}{l}\text { Nitrogen, } \mathrm{CO}_{2}, \mathrm{CO} \\
\text { methane, } \mathrm{H}_{2} \mathrm{~S}, \mathrm{NH}_{3} \\
\mathrm{SO}_{2} \text {, phosgene, ozone }\end{array}$ & $\begin{array}{l}\text { Asphyxiation, irritation, } \\
\text { pulmonary edema }\end{array}$ \\
\hline \multirow[t]{2}{*}{ Viable Aerosols } & Bacteria, viruses & $\begin{array}{l}\text { Brucellosis, psitticosis, anthrax, } \\
\text { mycobacterioses }\end{array}$ \\
\hline & Fungi & $\begin{array}{l}\text { Histoplasmosis, aspergillosis, } \\
\text { cocidioidomycosis }\end{array}$ \\
\hline $\begin{array}{l}\text { Respiratory } \\
\text { Carcinogens }\end{array}$ & $\begin{array}{l}\text { Arsenic, asbestos, } \\
\text { chromium, radon daughters, } \\
\text { nickel, coke oven emissions }\end{array}$ & Lung cancer* \\
\hline
\end{tabular}

\section{Background for Asbestosis, Byssinosis, SIllcosis, and Coal Workers' Pnoumoconlosis}

Specific examples will be given for the four occupational lung diseases identified in the Public Health Service 1990 Objectives: asbestosis (asbestos), byssinosis (cotton dusts), silicosis (silica), and coal workers' pneumoconiosis (coal dust) by exposure agent. 
A. Asbestos

The spectrum of asbestos-related diseases includes nonmalignant fibrogenic effects on lung parenchyma and pleural plaques, together with malignant neoplasms of the lung and serosal linings of the chest and abdomen (mesothelioma). The latent period is 15 years or more for asbestosis and 20 to 40 years for malignancies. The combination of smoking and exposure to asbestos significantly increases the risk of lung cancer. The complexities of the natural history and pathogenesis of asbestos-related diseases pose formidable obstacles to effective surveillance and control. The long latency period associated with asbestosis and malignancies indicates that disease observed today and in the next several decades is the result of past exposures.

The success of intervention measures instituted now cannot be evaluated for many years. Such assessments will be reliable only if medical and environmenta! surveillance mechanisms are complete and lifelong. The synergistic effect of smoking on lung cancer risk requires alteration of personal habits (smoking cessation) as an integral part of a prevention strategy for asbestos-associated disease.

B. Cotton Dusts

Byssinosis is characterized by both acute (reversible) and chronic lung disease caused by inhalation of cotton, flax, or hemp dusts. Byssinosis is largely preventable by limiting human exposure to cotton dust. Major improvements in dust control have occurred over the past decade in much of the cotton textile industry in the United States. However, even at very low concentrations of cotton dust, a considerable proportion of cotton textile workers may be at risk of developing byssinosis.

Strict control of dust should be supplemented by periodic medical examinations to identify affected individuals and to remove them from dust exposure. This can largely prevent chronic respiratory disease. Identification of the specific causal agent( $(s)$ in cotton dust is essential if more effective standards and control measures are to be instituted. The development and cultivation of varieties of cotton plants (and other vegetable fibers) with low "byssinogenic" activity could also substantially reduce the occurrence of byssinosis.

\section{Silica}

Although the effects of exposure to free crystalline silica have been known for centuries, the prevalence of disabling acute and chronic silicosis (nodular pulmonary fibrosis) remains high in certain groups of workers (workers in mines, stone quarries, sand and gravel operations, foundries, abrasive blasting operations, and glass manufacturing). Because silica is one of the most abundant minerals in the earth's crust, exposures are likely to occur, often without being recognized. When such exposures are recognized, it is possible to prevent the disease by controlling the environment. Because of the latency of chronic silicosis, the lack of effective treatment, and the progression of disease even after exposure has ceased, prevention of exposure is the most important strategy. Technologies for controlling silica-containing dusts are well developed for most industries, but often these control measures are either not applied or are not widely known. 
D. Coal Dust

Several studies showing a clear dose-response relationship between coal dust exposure and the development of simple coal workers' pneumoconiosis (CWP) indicate that the complicated form of the disease can be prevented if dust exposure is sufficiently reduced. Reduced levels of CWP in recent years, under lower dust standards in both Great Britain and the United States, illustrate that prevention of the disease is a realistic goal from both technical and economic viewpoints. The data also suggest that if primary prevention is unsuccessful and a worker is detected with early simple CWP, serious disabling disease can still be prevented by moving the worker to a lower-dust environment.

\section{Occupational Lung Diseases Prevention Strategy}

A. Preventive Components: What We Know and Can Implement Now

1. Agent-Oriented Strategies

a. Environmental Hazard Surveillance

Efforts should be continued to identify occupations in which workers are likely to have a high incidence of occupational respiratory disease. Special attention should be given to environmental surveillance and exposure control. Environmental surveillance is the most effective means of identifying problem areas, directing control efforts, and subsequently measuring the impact of prevention strategies.

i. Asbestos

Occupations where workers are likely to be at high risk of exposure to asbestos (such as asbestos removal operations) need to be identified. Special attention should be given to environmental surveillance and control of such occupations.

ii. Cotton Dusts

Industries using cottons that contain high levels of endotoxins should be identified and evaluated for possible additional intervention strategies or enactment or enforcement of a more stringent dust standard.

iii. Silica

Occupations likely to have a high incidence of silicosis could be identified through Standard Industrial Classification (SIC) codes; lists of industries that manufacture silica products; and data from the Mine Safety and Health Administration (MSHA), the Occupational Safety and Health Administration (OSHA), the Bureau of Labor Statistics (BLS), the Bureau of Mines (BOM), the National Center for Health Statistics (NCHS), the National Occupational Hazard Survey (NOHS), National Occupational Exposure Survey (NOES), and the National Occupational Health Survey of Mining (NOHSM). The need for increased environmental surveillance and exposure controls in, for example, the industrial sand industries and foundries, is already 
known. Any worksites (such as coal mines) where silica levels exceed the standard must be identified, and the silica standard must be enforced by the Mine Safety and Health Administration.

\section{b. Medical Hazard Surveillance}

Disease surveillance is needed to estimate the prevalence of occupational lung disease. However, because of the latency, the lack of treatments, and the progression of some occupational lung diseases after exposure has ceased, disease surveillance to identify exposures is of limited practical value, and emphasis should be placed on environmental surveillance.

Several data sources for disease surveillance exist, such as disability/ impairment (workers' compensation) data, insurance data, company surveillance data required by OSHA, company surveillance data voluntarily collected by industry, and state reporting systems.

Hospitals are another potential source of data and should be required to record work histories and to report occupationally related diseases in their discharge reports. State reporting systems using local physicians and county health officers are potentially the most effective means of disease surveillance. The primary advantage of using local physicians and county health officials is their familiarity with local industry and the medical community. Involvement of local county health departments would also facilitate follow-up of reported cases. However, this surveillance method has several difficulties, the most significant being the reluctance of physicians and workers to report diseases because of the potential for litigation and reprisals. Crucial to the success of such reporting systems would be clear diagnostic criteria (case definitions) and physicians who can recognize patients with diseases related to their work environments.

\section{c. Hazard Removal}

For many hazardous substances, control measures are difficult or unavailable. However, substitute materials are often available for the hazardous substances and should be used.

\section{i. Asbestos}

A rule-making change should be undertaken by OSHA to require that a dust control and monitoring plan for all operations with likely asbestos exposure be filed for approval before any work is done on the site. Implicit in this requirement would be a sound justification for the use of asbestos as opposed to alternative materials. Nonessential uses would not be approved. In addition, existing construction standards and codes should permit noncarcinogenic substitutes, especially where asbestos is recommended as an insulator by Underwriters Laboratories (UL) and building codes (both electrical and mechanical).

\section{ii. Cotton Dusts}

Because different grades of cottons and cottons from different regions have been shown to cause significantly varied acute responses in human subjects, industries in which workers show acute reactions at 
dust levels below $0.2 \mathrm{mg} / \mathrm{m}^{3}$ should consider the use of cotton substitutes or lower dust levels. Cotton substitutes include high grade cottons, blends of high and low grade cottons, cottons which have been washed, and synthetic cotton substitutes.

\section{iii. Silica}

Because effective controls for silica in abrasive blasting operations have not been demonstrated, silica should be banned as an abrasive blasting material; this was done in Great Britain over 30 years ago. Available silica substitutes that have been shown to be nontoxic should be used.

\section{Exposure-Oriented Strategies}

a. Control Technology

Many exposure control measures are available, such as engineering design and automation, ventilation, substitution, isolation, and changes in work practices. Implementation of the Atomic Energy Commission-As Low As Reasonably Achievable (AEC ALARA) levels should be considered in highly hazardous processes. Technology transfer and implementation goals should be established, so that both workers and management are familiar with control technology and its application. Specific effort should be made to ensure that technology transfer is a two-way process in which the success of implementing new technology is assessed at periodic intervals. Efforts should be made to reach small operations that may not have access to new technology information.

b. Regulatory Enforcement

Regulatory enforcement is the most effective element in the strategy to prevent occupational lung disease. The Mine Safety and Health Act and the Occupational Safety and Health Act both place the responsibility for providing a safe and healthful workplace squarely on the shoulders of the employer. Other measures of enforcement include sampling requirements for operators, an inspector "audit" program, pre-operation filing of hazard control plans, and the right for inspectors to stop unsafe operations onsite. Also, MSHA and OSHA should establish a framework for technology transfer to help operators come into compliance and to educate management, safety personnel, and the workers themselves.

\section{i. Asbestos}

Evidence indicates that the current asbestos standard provides only partial protection from asbestos-related diseases, particularly cancer. The present permissible exposure limit (PEL) should be reduced to the NIOSH-recommended concentration of 100,000 fibers $/ \mathrm{m}^{3}$ since that is the lowest level of exposure that can be accurately measured using currently available analytical techniques.

ii. Silica

Silicosis continues to be a problem because exposures above legal 
limits continue to occur. This situation exists both where the overexposures are well documented by companies, states, and federal agencies, and where silica exposures are not recognized. Once exposure is recognized, control could be accomplished in practically every instance through engineering controls or substitution. The most effective preventive measure for silicosis is preventing hazardous exposure, through strict enforcement of an appropriate exposure standard. Present federal standards, based on percent silica, range from allowable exposures of $33 \mu \mathrm{g} / \mathrm{m}^{3}$ to $98 \mu \mathrm{g} / \mathrm{m}^{3}$ free silica. These levels should be unified to a single standard that provides protection against silicosis over a working lifetime.

iii. Coal Dust

The most effective prevention strategy for CWP is to continue the present efforts with some improvements. NIOSH data suggest that the incidence of CWP is declining, probably due to the 1970 standard ( $2 \mathrm{mg} / \mathrm{m}^{3}$ with medical monitoring). In addition, efforts should be made to increase the awareness of dust-control techniques among smallscale operators. Texts that are easy to understand are needed on the latest and most effective control techniques.

\section{c. Education and Training}

An education program must be targeted to future engineers and managers to increase the appropriate use of control technologies. Intervention should be directed toward schools of engineering, public health, business, and vocational education. Successful exposure control techniques, once demonstrated at state and local levels, could be distributed nationally. The occupational health professional must also be appropriately trained and actively involved as a "change agent" in trying to improve working environments and developing informed worker and management groups.

The educational program of occupational health professionals should include special emphasis on epidemiology, biostatistics, industrial hygiene and safety, toxicology, and occupational health. The professional needs to learn what the work environment is, how to assess work exposures, and how to control them. The proper use of engineering controls and personal protective devices is a necessary component of such education.

For sustained effectiveness, training should emphasize the need for simultaneous involvement of management, occupational health professionals, production personnel, and workers, if occupational health programs are to be successful. Indeed, a successful program presupposes workers who are informed about work hazards and safe work practices and are encouraged to work cooperatively to reduce hazards. Such programs must be tailored to small, medium, and large workplaces.

State and local health departments can offer a ready source of expertise (physicians, nurses, sanitarians, epidemiologists, and others). These departments and primary care physicians should be used to identify small and local plant problems. Primary care physicians should be taught to recognize work-related diseases as part of their routine medical training. 


\section{d. Incentive Systems}

Although workers' compensation laws do provide some financial relief for disabled workers, they are essentially applied only after existing prevention systems have failed and when physical remedies are nonexistent. For this reason, and because the individual state compensation laws are diverse, significant modifications to the present system will not be achievable as part of a prevention strategy.

Because many exposures occur without the health consequences being known, manufacturers should promote increased awareness of the hazards associated with the use or improper use of hazardous materials by labeling products and issuing warnings. This prevention mechanism is particularly important for workers employed by small companies that use silica and asbestos products.

Economic incentives, such as lower insurance premiums, should be explored as a means for industry to implement new controls.

The authority of federal mine inspectors to "red tag" (shut down) a section of a coal mine if the hazard is severe, life-threatening, or caused by the "unwarrantable failure" of the operator to comply with mandatory safety or health standards, is an example of a powerful incentive for compliance that should be continued.

\section{e. Respirators}

Respirators and other personal protective devices should not be considered a primary control mechanism because they rely on human intervention. Recent studies have indicated that, under actual working conditions, respirators may not provide a level of protection equal to that determined in laboratory tests.

\section{Worker-Oriented Strategies}

\section{a. Health Promotion and Smoking}

Smoking is strongly associated with many lung diseases, including chronic bronchitis, emphysema, and lung cancer. Moreover, smoking has an additive effect on the risk for chronic bronchitis in workers exposed to coal mine and other dusts, and it acts synergistically with asbestos to increase the risk of lung cancer. Evidence also indicates adverse health effects on those who are exposed to the smoke of others. Because of the overwhelming evidence of the dangerous health consequences from smoking and the number of workers affected, a focus on smoking is an important component of a prevention strategy.

As Dr. Charles Carrington, past Chairperson, Mine Health Research Advisory Committee (MHRAC), said, "To attempt to control lung diseases without addressing smoking is so naive as to appear ludicrous." (MHRAC meeting, 1983). Elimination of smoking in the workplace is thus an important strategy, and one that supports the Surgeon General's goal of a smoke-free society in the United States by the year 2000 . 
The most prudent approach would be state legislation against smoking as it contributes to indoor air pollution, rather than specific laws against smoking in the workplace. Such state laws could designate all public places as nonsmoking areas, and management could then declare the company a "public place." Regardless of legislative outcome, management and labor should work together to develop appropriate nonsmoking policies that include some or all of the following:

- Prohibit smoking at workplaces, with sufficient disincentives for those who do not comply.

- Distribute information on health promotion and the harmful effects of smoking.

- Offer smoking-cessation classes to all employees at no cost to the participant. Smoking is addictive, and to prohibit smoking without offering this assistance to the smoking employee would be unjust.

- Establish incentives to encourage employees to stop smoking. For example, distribute to nonsmoking employees a portion of savings realized from smoking cessation (fewer lost workdays and lower health care and disability costs).

NIOSH will demonstrate its leadership in this area by adopting a model strategy within the Institute.

Note: Smoking in conjunction with exposure to asbestos could be addressed as part of a general health risk appraisal program, such as in the Centers for Disease Control software for Health Risk Appraisal. Considering the synergism between smoking and exposure to asbestos, a ban of workplace smoking and aggressive smoking cessation programs are warranted for workers exposed to asbestos.

b. Worker Knowledge of Exposure and Control Measures

Workers should be specifically informed of the hazards to which they are exposed and the control measures available. This should be accomplished by employers distributing information to employees and by public education at the secondary school level. Industries using hazardous substances, such as ground silica (silica flour), where acute and rapidly progressing cases of silicosis have been found, should be required to distribute information to their workers on an "action level" dust control performance measurement. Worker right-to-know laws should be enacted to ensure that workers exposed to hazardous substances, such as silica and asbestos, are informed and aware of the importance of control measures.

\section{c. Disease Surveillance}

Medical surveillance described previously to identify unsafe exposures and estimate disease prevalence was oriented toward the agent. Disease surveillance oriented toward the worker is designed to discover those workers who may be at increased risk if exposure continues. This increased risk may result from a pre-existing condition, early development of disease, or hypersusceptibility to a particular agent. When these 
workers are identified, some form of intervention is warranted, usually involving a reduction of further exposure.

\section{i. Cotton Dusts}

A key secondary prevention strategy for byssinosis has been the identification of workers with acute reactions to cotton dusts or reduced ventilatory function. The rationale for this medical surveillance is to prevent development of chronic respiratory disease by identifying workers with acute reactions and preventing further exposure.

\section{ii. Coal Dust}

A secondary prevention strategy for coal workers' pneumoconiosis is the use of the chest radiograph to identify miners with simple CWP. Once identified, these miners are given the option of working in a lowdust environment to prevent progression of simple CWP to the disabling, complicated CWP.

\section{B. Preventive Components: What Knowledge Do We Need}

\section{Agent-Oriented Strategies}

a. General Recommendations:

The toxicity of new substitute materials should be evaluated before they are introduced into the workplace-for example, silica substitutes.

Methods should be developed to determine relative causality in carcinogen exposure. Currently, causal factors cannot be separated or probabilities predicted because of insufficient knowledge about carcinogenic mechanisms.

A simple, inexpensive, and rapid method for determining airborne concentrations should be developed to enhance environmental surveillance for and control of exposure to several agents (silica and asbestos).

b. Specific Recommendations:

\section{Cotton Dusts}

The exact etiologic agent(s) of byssinosis are unknown, and thus efforts are thwarted to either cultivate or process cotton to remove such agent(s). Further research is needed to better define the specific agent(s) so that more effective control and exposure standards can be developed. For example, once an etiologic agent has been identified, it may be possible to more effectively control exposure, possibly by blending contaminated and uncontaminated cotton to lower exposures to this agent.

Silica

Current MSHA and OSHA environmental data should be evaluated to develop more effective means of identifying those sites where workers may develop silicosis. Within various industries identified as likely to have 
a high incidence of silicosis, specific sources of exposure must be identified before control techniques can be applied. This will involve detailed surveys of each suspected industry and processor. Some evidence, for example, shows that crushing may selectively break and aerosolize the silica fraction of the ore. An awareness of basic facts like these is needed before effective control measures can be developed.

For medical surveillance to be effective, an operational definition of silicosis is needed to standardize the diagnosis of silicosis reported to a surveillance system.

Coal Dust

Better sampling strategies and methods are needed for underground and surface mines, including mine surveillance, assessing personal exposure, and evaluating the effectiveness of technology.

\section{Exposure-Oriented Strategies}

a. General Recommendations:

Research on control technology for new applications and methods should be continued. Alternative approaches to process engineering controls are essential. For example, a worker's exposure may not be related to the primary worksite but to intermittent dust sources, such as roadways, stockpile, agricultural fields, or dust collector discharges. Traditional engineering approaches have not always been effective in controlling these sources.

Control technologies and strategies must be promoted through education and incentive programs. The best methods to implement and administer such programs are needed.

Predictive models to determine workplace exposures need to be developed before design or installation of process equipment.

If current standards for an agent are nonexistent, or if the exposureresponse data are incomplete, additional research may be needed to develop more effective exposure standards.

b. Specific Recommendations:

\section{Asbestos}

The exposure-response for asbestosis and the effects of fiber types in the disease process need to be ascertained.

Research is needed to determine the potential health benefits and the risks of asbestos-removal programs in office buildings and schools.

Since significant new exposures may occur when old structures are renovated or demolished, control should be evaluated for asbestos-removal operations. Effective asbestos-removal work practices are needed. 
A quantitative method should be developed to determine the fiber release potential of in-place friable asbestos materials. The method should then be incorporated into a "control options" assessment strategy.

\section{Cotton Dusts}

Protective standards with strict enforcement by OSHA are essential to prevention of byssinosis. Once the specific causal agent(s) of byssinosis has been adequately identified, the effectiveness of the current dust standard should be evaluated.

New efficient and effective means of removing or controlling the specific causal agent(s) of byssinosis will be needed when the agent(s) has been identified.

Silica

The dose-response relationships for silica and silicosis need to be determined, particularly for low levels of exposure and exposure to mixed dusts containing silica.

\section{Coal Dust}

The use of longwall mining techniques is increasing in the United States, and improved dust control technologies are needed. In addition, new technologies are needed for control of silica dust on sections using continuous mining equipment, particularly those operating at reduced standards. For all mining methods, forecasting and predictive techniques should be established, and specific means of implementing control technology into mine planning and equipment design should be developed.

Because productive mining methods of the future may generate more dust at the increased rate at which coal is broken, specific long-range strategies for control technology should be developed, and directed basic research should be conducted to support these strategies. For example, the fundamental mechanisms by which dust is generated and transported must be understood and joined to specific control technology objectives. Also, respirable dust characteristics should be correlated to coal seam and mining methods.

\section{Worker-Oriented Strategies}

\section{a. General Recommendations:}

More sensitive techniques need to be developed for detecting early changes at the cellular level and for recognizing very early signs of disease. Methods are also needed to predict susceptibility to occupational asthma or the organic dust diseases. For example, are workers who react acutely to organic dusts more susceptible to long-term effects?

Because the current literature is not consistent about the relationship between smoking and diffuse lung fibrosis, research is needed to determine whether smoking influences this disease process. 
Research is needed to determine whether serious effects result from lowlevel, but episodic, exposures to irritant gases and fumes, and whether long-term effects follow acute responses to pulmonary irritants.

The scope of the hypersensitivity pneumonitis problem needs to be determined.

b. Specific Recommendations:

Asbestos

Dose-response relationships for asbestosis and pleural changes require better definition. Estimates of risk for asbestosis and asbestos-related cancer are needed for low doses, intermittent exposures, and short-term, high exposures. The health effects of "short" asbestos fibers and the relationship between asbestos exposure, pleural changes, and the development of lung cancer should also be studied. Information on the relative pathogenicity of different asbestos types and asbestos substitutes should be refined. The significance of pleural plaques to mortality and morbidity needs to be determined.

\section{Cotton Dusts}

The current status of medical surveillance as mandated by the Cotton Dust Standard must be assessed. A clear relationship between acute responses and chronic respiratory disease in cotton workers has not been established, and a prospective study is necessary to investigate this relationship. New NIOSH recommendations may be necessary to make medical surveillance for cotton workers more effective in preventing chronic respiratory disease. In addition, little published information is available on the normal decrements in lung function to be expected annually. The lack of this information has made interpretation of lung function data for cotton workers less effective. More information is needed about host risk factors, such as smoking and atopy. These risk factors, along with medical surveillance, can be used to identify the workers most at risk of developing chronic respiratory disease.

Silica

Because several animal and epidemiologic studies have raised the question whether quartz is a carcinogen, further well designed epidemiologic studies are needed to determine whether this is true.

\section{Coal Dust}

Because some disabled miners have no radiographic evidence of CWP, the severity of nonpneumoconiotic lung disease (bronchitis and emphysema) in coal miners and its relationship to dust level, composition, and size distribution need to be investigated. Research into the dose-response and lung function relationships of dusts and acute and chronic bronchitis should be conducted with the goal of setting a total dust regulation for general industry as well as for underground coal mines. Better long-term studies of both miners and ex-miners are needed to accurately assess the totality of adverse health effects from dust exposure in coal mining. The 
relationship of coal dust exposure to the development of emphysema also needs to be resolved. Only with such knowledge can we intelligently attack all work-related pulmonary diseases in miners.

\section{Summary}

This prevention strategy will not succeed or fail on the basis of any one of the elements described. All elements must be addressed if occupational lung diseases are to be prevented. For example, problem areas can be identified through environmental and medical surveillance; however, without follow-up and corresponding elimination or reductions in exposure, surveillance would be of little practical value.

Surveillance must be coupled with exposure control (e.g., exposure standards with strict enforcement, work practices, automation, ventilation, incentive systems) and other important elements described in this prevention strategy. Health promotion and the development of a workplace smoking policy, while not always directly related to occupational exposures, are additional important elements. 


\section{Contributors}

NIOSH WORKING GROUP MEMBERS

John L. Hankinson, Ph.D., Chair

Thomas K. Hodous, M.D.

Laurence Doemeny, Ph.D.

Pervis C. Major, Ph.D.

John Gamble, Ph.D.

James M. Melius, M.D., Dr. P.H.

Francis Green, M.D.

William J. Moorman

Frank Hearl, P.E.

Martin J. Sepulveda, M.D., M.P.H.

\section{SYMPOSIUM PANELISTS}

Robert E. Glenn, M.P.H., Chair National Institute for Occupational Safety and Health

Henry A. Anderson, M.D.

Wisconsin Department of Health

Charles E. Andrews, M.D.

University of Nebraska Medical Center

Michael P. Eriksen, Sc.D.

Pacific Bell

David A. Fraser, Sc.D.

The University of North Carolina
Thomas J. Shepich

Mine Safety and Health Administration

Clinton W. Stallard, Jr., M.D.

Standard Oil Company of Ohio

James L. Weeks, Sc.D.

United Mine Workers of America

Hans Weill, M.D.

Tulane University

John T. Wilson, Jr., M.D.

University of Washington 